\title{
An Analysis on Stylistic Features of Donald Trump's Speech
}

\author{
Jianan Rong ${ }^{1}$ \\ ${ }^{1}$ Department of Linguistics, School of International Studies, Zhejiang University, Hangzhou, China \\ Correspondence: Jianan Rong, Department of Linguistics, School of International Studies, Zhejiang University, \\ Hangzhou, 310058, China. E-mail: jiananron@zju.edu.cn
}

Received: November 13, $2020 \quad$ Accepted: March 5, $2021 \quad$ Online Published: March 8, 2021

doi:10.5539/ijel.v11n3p11 URL: https://doi.org/10.5539/ijel.v11n3p11

\begin{abstract}
For government or leaders, public speaking is an important way to show the statesmanship and eloquence. It is a means of attracting groups of people who come from different classes. As the president of the United States, Donald Trump's speaking talent plays an important role in the general election. Stylistics, which uses theories of modern linguistics to solve problems, aims at studying linguistic features and revealing the effect and function of pragmatic expression. This article selected Donald Trump's three typical speeches, which studies from the perspective of stylistics on three major aspects - language description, textual analysis and contextual analysis. The analysis yielded the following results, 1) Language description consists of lexical analysis and syntactic analysis. On lexical level, Trump tends to use more abstract nouns and first person plural pronoun to make the addresses persuasive and more acceptable. Syntactically, for the sake of expressing information effectively and attracting more support, simple sentences and declarative sentences are prevailing in the speeches; 2) On the aspect of textual analysis, Trump employs topical division, problem-solution division and chronological division in an overlapping way in main body of speeches and creates crescendo in closure; 3 ) Contextual analysis shows that language varies from situations and they are formal and highly-structured. In a word, to analyze Donald Trump's speech on stylistic features is significant for us on observing the features of his speeches and word-using habits.
\end{abstract}

Keywords: Donald Trump, stylistic features, public speaking

\section{Introduction}

Among various genres of communication, public speaking is a common kind, however, it serves a significant role in many aspects of people's daily life. The function of public speaking is not only to express the idea of the addresser, but to influence people's thoughts and motivate their action. Macroscopically, public speaking can even put a great impact on the history. The speech "I Have a Dream" of Martin Luther King and the speech addressed by Abraham Lincoln in Gettysburg, all these great speeches have inspired countless people from generation to generation.

The president of the United States, Donald Trump, whose speeches are certainly not to be ignored as well. Since he is more an excellent businessman than a politician in the past several decades, his performance, especially on the aspects of political talents and speech gifts are in great concern. Therefore, as the public speech demonstrates one's resolution that being a leader requires, Trump's speeches and his eloquence are surely worth studying.

In this article, the addresses delivered by Donald Trump were selected on different occasions. The sample texts are Trump's monumental addresses that played a significant role in the preliminary stage of his political career. The first one is inaugural speech after he won the election, which contains Trump's political plan and tells what measures he would take to build a greater America. The second one serves as the first remarks to the congress. It talks about the difficulties confronting the USA and promulgates some appointments. And the last address is the speech to the world economic forum at Davos which involves some economic policies that the USA suggests. These three speeches will be abbreviated as Inaugural Speech, Congressional Speech and Davos Speech respectively.

The theoretical basis of this article is modern general stylistics which serves as the branch of modern linguistics. Stylistics studies the use of language in specific context and attempts to account for the characteristics that mark the language use of individuals and social groups (Qian, 1991). Stylistics is defined as "the branch of linguistics that studies language style $(\mathrm{Hu}, 2002)$. It explains the relationship between the text and its context." And Wales 
Katie (1989) simply defines stylistics as "the study of style". Widdowson (1975) displays his understanding of stylistics from another perspective, "By stylistics, I mean the study of literary discourse from a linguistic orientation and I shall take the view that what distinguishes stylistics from literary criticism on the one hand and linguistics on the other is that it is essentially a means of linking the two." Stylistics analysis is generally concerned with the uniqueness of a text, that is, what it is that is peculiar to the use of language in a literary text for delivering the message. Modern stylistics is initiated by the development of two most influential theories of linguistics in the late 1950s: Chomsky's transformational generative grammar and Halliday's systemic functional linguistics.

According to Halliday (1985), language varies as its function varies; it differs in different situation. Public speech aims at persuading, entertaining and informing, and it usually tends to be more highly structured and more formal. Moreover, the speaker of public speech shall make detailed preparations. In The Rhetoric, Aristotle (1954) classified the means of persuasion into three types: ethos, pathos, and logos. Ethos refers to a speaker's credibility, pathos to a speaker's emotional appeals, and logos means a speaker's logical appeals. In modern society, people put a high value on public speech. Public speech is a time-honored activity in western civilization, which plays a significant role in people's daily lives.

Since the three selected speeches are all delivered at a critical period by Donald Trump, they are typical enough to be samples in this paper. The article consists of several parts in total to give a detailed analysis about Trump's three addresses with the help of basic theories of stylistics. They are linguistic descriptions, textual analysis and contextual analysis respectively. In linguistic descriptions, lexical features and syntactic features are analyzed, and in textual analysis, the body and the conclusion parts of the speeches are focused. Finally, field, tenor and mode of three speeches are studied in contextual analysis.

\section{Linguistic Descriptions}

Linguistic description means to explore and classify the linguistic features in a given text. In order to capture the stylistic features of Donald Trump's public speech completely, the linguistic description in this article will be carried out at these two levels: lexical and syntactic analysis.

\subsection{Lexical Analysis}

At the level of linguistic description, the choice of lexis is mainly concerned with the analysis of content words, which involves the following aspects: if the words are complex or simple; formal or informal; general or specific. The lexis used in Trump's speeches refers to the choice of his words. Moreover, the lexical items used in public speech are more complicated than those in daily conversation, which includes abstract nouns, personal pronouns, etc. Those words will make the public speech more persuasive and credible.

\subsubsection{Abstract Nouns}

In Trump's speeches, derivational words and abstract nouns are frequently used. A number of derivational words usually refer to the state, action, quality or cause in public addresses. The nouns that derive from verbs are a stylistically characteristic of the language in public speeches. Words like transition, establishment, triumph, celebration, movement, poverty, destiny, expense, depletion, decision, immigration, vision, protection, prosperity, goodwill, disagreement, solidarity, freedom, truth, liberty, justice, renewal, independence, rebellion, concerns, election, corruption, regulation, enforcement, integrity, construction, obligation, admission, sanction, devotion, etc. can be found in Trump's speeches.

The wide use of abstract nouns is another one of the significant stylistic features of public speech. This can help to form long words with much more complicated structures, hence making a contrast with our daily conversations. Another reason that Trump uses abstract nouns might be that his addresses involve various ranges of issues such as education, Iran's ballistic missile program, immigration, changes, reforms, etc., thus using the abstract nouns makes his speech more profound and formal. Meanwhile, he appears thoughtful and knowledgeable, which will make the audience have more confidence in him.

\subsubsection{Personal Pronouns}

Another important feature of public speech is using personal pronoun frequently. Especially the first person, both singular form and plural form, is most often used than the second or the third person. When delivering the speech, the speaker has to mention himself every now and then to express his feelings and views. Therefore, it is natural for him to use " $\Gamma$ " or " $m e$ ". However, the use of the first person in plural form is more complex and profound. In English, "we" or "us" usually include both the speaker and the audience, but occasionally, they mean the unilateral side of the speaker. The use of " $w e$ " or " $u s$ " demonstrates that the addresser takes the addressees' stand and hence shortens the distance between them. For example, "When we have all of this, we will have made 
America greater than ever before-for all Americans." "We must speak our minds openly, debate our disagreements honestly, but always pursue solidarity." (Congressional Speech). To show the use of personal pronouns more directly and more accurately, a self-built micro-corpus, which covers the three addresses, is analyzed with the help of AntConc, and the results are as follows:

Table 1. Concordance Hits of Personal Pronoun

\begin{tabular}{llll}
\hline Personal pronoun & Singular/Plural & $/$ & Concordance Hits \\
\hline First person & Singular form & $\mathrm{I} / \mathrm{me}$ & 58 \\
& Plural form & We/us/our & 440 \\
Second person & $/$ & you & 48 \\
Third person & Singular form & He/she & 14 \\
& Plural form & They/them & 60 \\
\hline
\end{tabular}

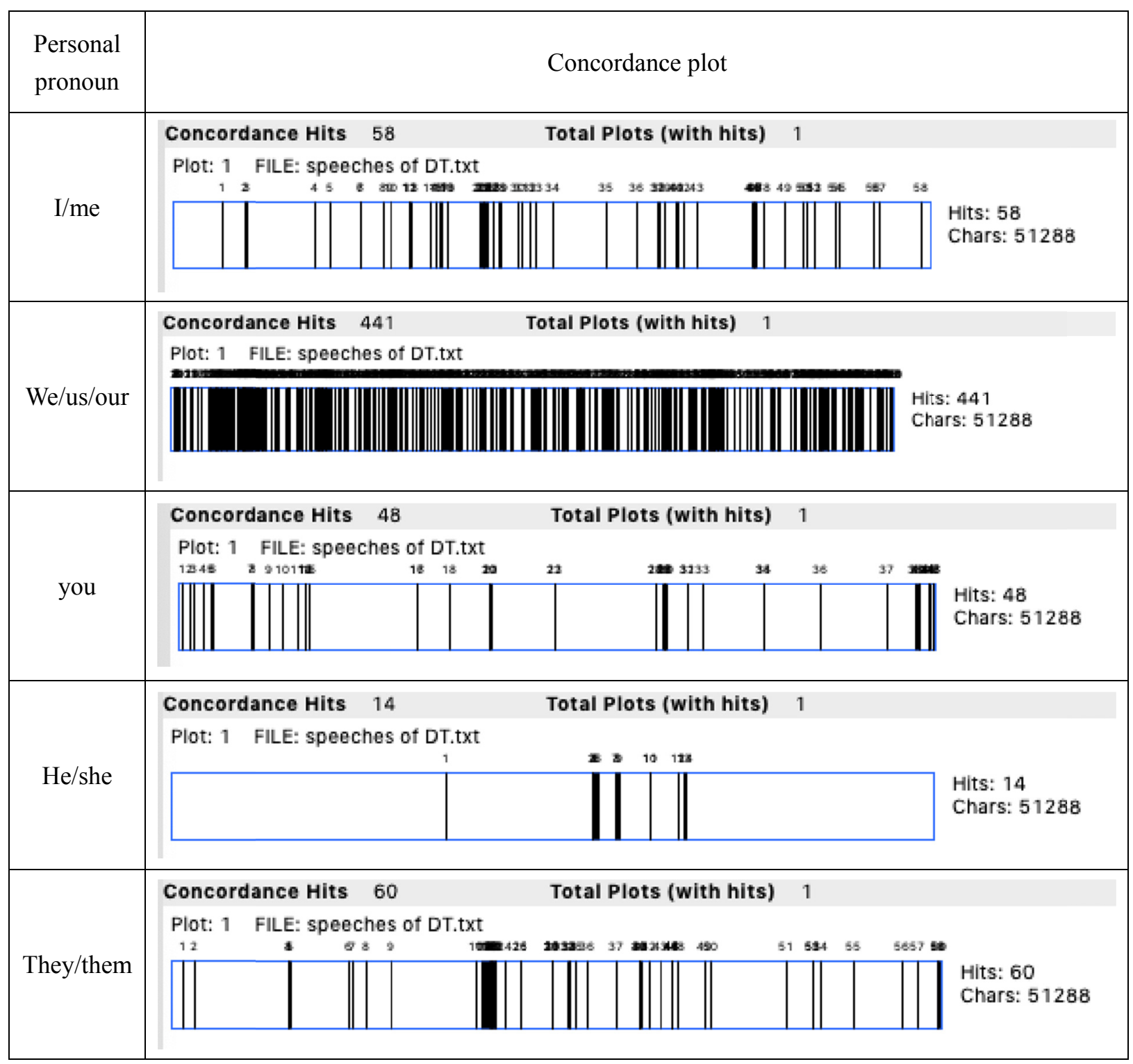

Figure 1. Concordance plot of personal pronoun

According to the Table 1 above, the number of the first personal pronoun is 498 (the abbreviation of U.S. has been excluded already), which is far beyond the number of second and the third person form (122 hits in total). Besides, the use of first person in plural form is 440 , which is much more frequent than that of the singular form 
(58 hits). Generally, the first person in plural form can sharply arouse the listeners' affirmative feelings and the sympathetic response. Figure 1 makes the same point more intuitively. Compared with the second person and third person, concordance hits of the first person is the densest, and the concordance hits of the first person in plural form is extremely dense. In most cases, "we/us/our" stands for a mild way requesting commanding. The addresser calls upon his addressees through using "we", "us" or "our", making the speech more acceptable and forming a closely coalition with the hearer.

\subsection{Syntactic Analysis}

Syntax is one of the branches of modern linguistics, which studies the rule governing the combination of words in sentences. It offers various possibilities to be explored for effective linguistic communication.

According to A Dictionary of Stylistics (Wales, 1989, p. 201), "sentence is usually taken as one of the most significant units of grammatical analysis, and the largest: the others being clause, phrase, word and morpheme." In terms of different criteria, sentences can be classified into various types. According to the structural features that correlated with function or illocutionary force, the basic sentence type is declarative sentence in the form of a statement. The other main types are imperative sentence used for directive and interrogative sentence used for questions (Wales, 1989).

On the other hand, sentences can also be classified in to major sentences and minor sentences. Major sentences include multiple and simple sentences in terms of the number of constituent clauses. Major sentences adhere to the regular clause patterns of clause structures. While minor sentences do not adhere to the regular clause pattern, or for some reason the speaker never reaches the end if what he intends to talk.

Generally, sentences in speech texts are usually written in advance and well-organized. Most of the sentences follow the regular clause patterns of clause structures, and the declarative sentences are basic sentence in sample texts. Thus, major sentences and declarative sentences make the vast majority of the speeches, which are mainly focused in this article.

\subsubsection{Major Sentence}

Major sentences include simple and multiple sentences in terms of constituent clauses. The following table shows the number of sentences and the sentence mean length in three speeches.

Table 2. Speech statistics

\begin{tabular}{lll}
\hline & Number of sentences & Sentence mean length \\
\hline Inaugural Speech & 100 & 14.56 \\
Congressional Speech & 292 & 17.13 \\
Davos speech & 112 & 16.92 \\
\hline
\end{tabular}

From the table above, we can see that the Congressional speech is the longest one, which has 292 sentences. And sentence mean length of three speeches, as shown in the Table 2 above, are 14.56, 17.13 and 16.92, which are all shorter than the average sentence length in public speaking 17.6 (Huang, 2017). Hence simple sentences dominate the speeches. Perhaps using simple sentences is convenient for Trump to convey information to the audience and create an image that is close to the people. Besides, simple sentences are usually more inspiring, plain language of which can help him win more support and trust from the commons. Trump uses much this kind of sentences to strengthen the power and adding persuasiveness to his addresses.

\subsubsection{Declarative Sentence}

As all mentioned above, sentences can be classified as interrogative, imperative, exclamatory and declarative sentences in terms of their functions. Declarative sentences are usually used to make a statement or to tell a factual event; an interrogative sentence is a question; imperative sentence is used to command or instruct; and an exclamatory sentence is applied to demonstrate strong feelings.

According to the samples, it is clear that declarative sentences prevail in all the three samples. The reason is that public speeches are intended to persuade, to inform, and to appeal. Moreover, the use of declarative sentences may arouse the addressees' passion and appeal to them to follow the addresser's willingness as well. Hence most of the sentences are declarative. For instance:

The American economy is by far the largest in the world and we've just enacted the most significant tax cuts and reform in American history. (Davos Speech) 
Free nations are the best vehicle for expressing the will of the people, and America respects the right of all nations to chart their own path. (Congressional Speech)

At the bedrock of our politics will be a total allegiance to the United States of America, and through our loyalty to our country, we will rediscover our loyalty to each other. (Inaugural Speech)

To sum up, we made a comprehensively stylistic analysis of Trump's addresses from levels of lexical and syntactic. Through choosing some of the most remarkably occurred language features in Trump's speeches, we have made a probable exploration of Trump's many respects worthy studying.

\section{Textual Analysis}

An effective address requires not only well-chosen words and well-organized sentences, but it demands a coherent structure that words and sentences of a piece of written or oral communication fit together. The word "text" refers that any passage, spoken or written, of whatever length, which forms a unified entirety. A text refers to a semantic unit that is organized by a sequence of language units, not matter they are sentences or not. The link among parts of a text is realized by various cohesive devices, by semantic and pragmatic implication (Qian, 1991).

In a public speech, there are three parts that usually be covered: the introduction, the body, and the conclusion. In this paper, we are going to talk about the body of the Trump's speeches and then view them from the perspective of the whole texts. It will help the readers to attain a solid understanding of Trump's style.

\subsection{The Body of the Speech}

In the body of the public speech, the speaker often develops his key points according to a specific organized pattern. Addressers employ various organized structures and the most commonly used types are: topical, chronological, spatial, casual and gimmick division (Grice \& Skinner, 1995).

In this part, the addresser often develops the main issue that is mentioned in the introduction. The three selected speeches are all organized logically out of the needs of the topics. A detailed analysis of Donald Trump's nomination acceptance speech will be analyzed here for example.

Trump first told the present situation confronting the America and mentioned some major problems American people face today. He declared that "a small group in our nation's capital has reaped the rewards of government while the people have borne the cost", pointing out that the government and some politicians have grabbed some civil right which is supposed to be possessed by all the American people. Then he reflected what has been a central theme of his campaign as soon as he won the election - people's will and voices shall be taken seriously.

"Protection will lead to great prosperity and strength. I will fight for you with every breath in my body and I will never ever let you down." (Inaugural Speech)

Then Trump emphasized what he determines to do as concrete steps he would take, bringing back American people's wealth, building new infrastructures, getting American people off of welfare and back to work and rebuilding the country with American labor.

Then Trump quoted the words from the Bible, saying that "how good and pleasant it is when God's people live together in unity". He said, "We must speak our minds openly, debate our disagreements honestly, but always pursue solidarity." (Inaugural Speech)

In each sample address, the key issues are generally arranged by topical division and within each topic the different aspects are dealt with the same division. Regarding to the key idea with in every big paragraph, problem-solution division is functioning so as to organize the topics of current situation. Past and present situation are both arranged from the chronological perspective. Therefore, topical division, problem-solution division and chronological division are used in an overlapping way.

\subsection{A Conclusion of the Speeches}

The conclusion is the last division of public speech. Usually two steps should be included: summarizing and to providing closure. In the summary, statements that review the main ideas of a speech are usually provided. It offers the listener one last chance to hear and memorize the main points of addresses. Hence the summary reinforces the ideas of the address and brings it to a natural conclusion, if the summary concludes a speech naturally; the final statement ends the address logically.

By studying on the conclusions of the three speeches, we can see that Trump has summarized the speech to a certain extent. As for closures, Trump usually tends to create a crescendo, finish near the peak in order to create a resounding last impression. 
"Your voice, your hopes, and your dreams will define our American destiny. And your courage and goodness and love will forever guide us along the way.

Together, we will make America strong again. We will make America wealthy again. We will make America proud again. We will make America safe again. And yes, together we will make America great again." (Inaugural Speech)

"I am asking all citizens to embrace this renewal of the American spirit. I am asking all members of Congress to join me in dreaming big, and bold, and daring things for our country. I am asking everyone watching tonight to seize this moment. Believe in yourselves, believe in your future, and believe, once more, in America.

Thank you, God bless you, and God bless the United States." (Congressional Speech)

"Today, I am inviting all of you to become part of this incredible future we are building together. Thank you to our hosts, thank you to the leaders and innovators in the audience but most importantly, thank you, to all of the hard-working men and women who do their duty each and every day, making this a better world for everyone. Together let us send our love and our gratitude to make them because they really make our countries run. They make our countries great. Thank you and god bless you all. Thank you very much.” (Davos Speech)

By studying the conclusions above, it can be told that all the three speeches have parallel construction. In Inaugural Speech, Trump uses "we will..., we will..., we will..." to inspire the public and persuade them to believe in him; In Congressional Speech, "I am asking..., I am asking..., I am asking..." is used to form a crescendo to emphasize his political ambitions; In Davos Speech, he uses appeal and parallel constructions as well to show the image of superpower. All these powerful ending may greatly energize the audience, leaving the addressees a long last impression and impact.

These highly effective speech practices enable Trump to deliver a masterful address which profoundly accelerate his political career and mould him into a worldwide political figure.

\section{Contextual Analysis}

"Language varies, for function varies" (Halliday, 1985). Therefore, the context should be taken into consideration in the stylistic analysis. It has long been acknowledged that language is a significant and essential social-cultural phenomenon, as well as the carrier and reflection of various social activities. For each speech community, it has own history, culture, customs and moral standard. These aspects and factors contribute to form a certain speech community, and form the so-called social-cultural context. With respect to the meaning of context, it lies in its social function and the purpose of usage. The same text in different social-cultural may have different meaning and function (Huang, 2001).

The concept of "context of situation" is elaborated by Firth in his paper Personality and Language in Society (1957, p. 14). According to Firth, what this implies essentially is that language comes to life only when functioning in some environment.

Since these addresses are delivered by one person, they share certain similarities in style, for example, the effective use of concise and powerful language. The addresses are surely different as they concern on different matter and delivered on different occasions.

\subsection{Field of Discourse}

To some extent, the subject of a text is largely determined by the field of discourse and thus it has direct influence on the option of words and delivery. The general background of these three samples is that they all happened on some critical political situations. There are surely differences exist in addresses.

Sample one is delivered just after Trump's winning the election. He narrates the difficulties and problems confronting the United States, and then by listing the plans which he is going to implement, he calls on all the Americans to support his party.

Sample two is delivered in joint address to congress. Therefore, the address states a serious of problems and deficiencies in American, and Trump tells the audience what he has done to solve these problems. Meanwhile, he aims at providing massive tax relief for the middle class, creating a level playing field for American companies and workers. Urging for free and fair trade, President Trump quoted words from Abraham Lincoln that "abandonment of the protective policy by the American Government will produce want and ruin among people." Moreover, immigration system will be reformed to strengthen nation's security and to improve jobs and wages for Americans, Obamacare is collapsing and shall be repealed and replaced from Trump's perspective, etc., 
Trump makes a long and powerful speech to propose a series of administrative programs.

Sample three was made on the world economic forum at Davos. On behalf of the will of the United Sates, Trump demonstrated his economic-related achievements in America and invited all the others to build a more incredible future altogether with Americans.

Therefore, Donald Trump's word choices and language organization strategies vary from different subject matters and situations.

\subsection{Tenor of Discourse}

The tenor of discourse relates to the relationship with the addressee. It means the participants who are taking part in this exchange of meaning and what kind of relationships they have to one another. Precisely speaking, tenor refers to the personal relationships between speakers and hearers. Such relationships will influence the formality of the language in the text. Subject choosing determines differences in tenor. The tenor of discourse includes many factors, such as the participants, their social status, their educational background, the relationship between the speaker and the hearer, the degree of social distance and intimacy.

Donald Trump is a man over 70 years old who used to be a successful businessman. And he had no political experience previously.

In the Inaugural Speech, with the plain language and the attracting words, the commons probably can feel the trustworthiness and confidence of their president. While in Congressional speech, Trump systematically stated his political plans over tax reform, medical reform, military expenditure and trade policy. This may be influenced by the addressees here - to let the congress know better his governing concept. And the addressees of the Davos Speech became the whole world.

In these three speeches, the average fog index is relatively low, which indicates that there are no complicated political terms in the speeches and they are not difficult to comprehend as well. These features indicate that the speeches are delivered to the public, but at the same time, varied from different hearers.

\subsection{Mode of Discourse}

The mode of discourse means what part the language is playing in the particular situation. For instance, what channel is used, how the language is functioning in the interaction, in what way the language is organized to convey the meaning, word formality.

Though bearing different characteristics, all these selected samples belong to the major genre of public speaking. For one thing, they share the qualities of written language as they are all carefully prepared in written form in advance; for another, they all have spoken language features as they were all presented orally from the speaker to the audience. Although they show the characteristics of the written mode with highly organized logical thoughts, they still differ from the written pieces in that the latter one cannot adapt to the readers' immediate feedback. And besides, these speeches are also different from daily conversations, because of concentrating on one topic with highly and closely-knit structured form and more formal language which lead to a more effective way of delivery.

\section{Conclusions}

In the previous parts of the article, we analyzed Trump's language features of public speech from three levels, linguistic description, textual analysis and contextual analysis, within the framework of modern stylistics.

Language description consists of lexical analysis and syntactic analysis. On lexical level, Trump tends to use more abstract nouns to make his speeches profound and formal. On the other hand, the use of first person in plural form, which is far more frequent than that of the other pronouns, might help narrow the gap between Trump and the audience, thus creating a more approachable political image and winning more support. Syntactically, to express information effectively and show the authority, simple sentences and declarative sentences are prevailing in the speeches. Besides, the reason why using declarative sentences frequently in all these three samples might be that public speeches are usually intended to persuade, to inform and to appeal.

On the level of textual analysis, Trump employs topical division, problem-solution division and chronological division in an overlapping way in main body of speeches and creates crescendo in closure, making speeches more influential and infectious to the hearers; Last but not least, contextual analysis shows that language in speeches varies from situations but they are all formal and highly-structured. To conclude, analyzing Donald Trump's speeches on observing the stylistic features is fairly important on studying his speeches and word-using habits. 
This study provides a new perspective to the studies of English public speech. Besides, a clear picture of characteristics of Trump's language features is presented and it can help readers to comprehend and appreciate the English public speech better. This article may provide some instructional guidance for students and serve as a reference for further studies. In addition, readers could probably employ the same persuasion and presentation method to strengthen their communicative power.

However, speeches analyzed in this article are relatively few, only three samples are used, and other later speeches are not involved, which may affect the whole comprehension of Trump's language features to some degree. More materials should be used and deeper comments and descriptions should be performed in future studies.

\section{References}

Aristotle. (Trans, W. Rhys Roberts). (1954). The Rhetoric. New York: The Modern Library.

Donald, J. T. (2017a). Inaugural Speech. Retrieved November 20, 2020, from $\mathrm{https} / / /$ wenku.baidu.com/view/91e4df68366baflffc4ffe4733687e21af45ff29.html

Donald, J. T. (2017b). Remarks in Joint Address to Congress. Retrieved November 20, 2020, from http://www.kekenet.com/Article/201703/498415.shtml

Donald, J. T. (2018). Remarks at World Economic Forum at Davos. Retrieved November 20, 2020, from https://wenku.baidu.com/view/92d61adabdeb19e8b8f67c1cfad6195f312be80d.html

Firth, J. R. (1957). Papers in Linguistics (pp. 1934-1951). London: Oxford University.

Grice, G. L., \& Skinner, J. F. (1995). Mastering Public Speech. Needham Heights, Massachusetts: Allyn \& Bacon.

Halliday, M. A. K., \& Hason, R. (1985). Language, Context and Text. Victoria: Dekin University press.

Hu, Z. L. (2000). Theoretical Stylistics. Beijing: Foreign Language Teaching and Research Press. Retrieved from https://max.book118.com/html/2018/0331/159522084.shtm

Hu, Z. L., \& Jiang, W. Q. (2002). Linguistics: An Advanced Course Book. Beijing: Peking University Press.

Huang, G. W. (2001). A Comprehensive Discussion on Functional Discourse Analysis. Foreign Languages and Foreign Language Teaching.

Huang, Q. (2017). Stylistic Analysis of Donald Trump's Inaugural Address (Western Sichuan Literature Translation and Translation Research Center, Chengdu Translators Association Eds.). Research on Innovation in Foreign Language Education and Translation Development, 6, 388-391. Sichuan Normal University Electronic Publishing House. Retrieved from https://kns.cnki.net $/ \mathrm{kcms} /$ detail/detail.aspx?dbcode $=$ CPFD\&dbname $=$ CPFDLAST2017\&filename $=$ XBWX 201706001107\&v=ASjdsILe4xyDJnZ\%25mmd2BQ6blhlcKSi\%25mmd2FlfuIruivfQi5TLY\%25mmd2Bjlp ZNIEM\%25mmd2BBH1Qffm1UxEamSThvRD\%25mmd2BhAU\%3d

Qian, A. (1991). Stylistics: A Course Book for Chinese EFL students. Beijing: Beijing Normal University Press. Retrieved from https://max.book118.com/html/2018/0224/154484311.shtm

Wales, K. (2014). A Dictionary of Stylistics. Taylor and Francis. https://doi.org/10.4324/9781315833507

Wang, S. Y. (1990). English Stylistics. Jinan: Shandong Education Press. Retrieved from https://max.book118.com/html/2018/0224/154484333.shtm

Widdowson, H. G. (2014). Stylistics and the Teaching of Literature. Taylor and Francis. https://doi.org/10.4324/9781315835990

\section{Copyrights}

Copyright for this article is retained by the author, with first publication rights granted to the journal.

This is an open-access article distributed under the terms and conditions of the Creative Commons Attribution license (http://creativecommons.org/licenses/by/4.0/). 